Renal Function and Renal Failure

Lionel M. Bernstein. Pp. viii +143 illustrated. Edinburgh and London: E. \& S. Livingstone. 1966. $£ 3$ 0s. Od.

This book states in the preface that it extends the material of four lectures given to third year students. Throughout, one can see that these must be an extremely clear, lucid, well constructed series of lectures. Unfortunately, in book form it is difficult to follow the text due to frequent reference to a series of fifty-six diagrammatic figures at the end of the book. The constant turning from text to figure makes consecutive reading almost impossible, also in several instances diagrams which have to be compared are on opposite sides of the same page, thus increasing the difficulties.

This is not a reference book, having no bibliography as such, it is really only of use to. students learning the subject, but the lectures have been so markedly extended that there is much more information in the book than most medical students will be prepared to either pay for, or take long enough to read, despite the importance of the subject.

The book is completely modern in its theories, and probably of most value to the postgraduate who feels he has lost touch with modern concepts of renal physiology, disease, and electrolyte disturbances, and wishes to revise these starting from fundamental principles.

\section{A Short Textbook of Venereology. The Sexually Transmitted Diseases.}

R. D. Catterall. Pp. viii +198 illustrated. London: English Universities Press. 1965. 15s. (Paperback). 25s. (Board).

This is an enlarged and improved version of the author's textbook, "Venereology for Nurses," published in 1964. The modification is successful and has resulted in a comprehensive textbook covering the general subject of sexually transmitted and other genital conditions. The claim that this can be considered as a "disposable textbook" is justified although all necessary economy has been achieved in materials with no loss of quality in the contents.

The subject matter is well presented but, in some sections, comment may be made on the undue emphasis on unfortunate and distressing complications. As an example, the section on 'Gonorrhoea in men' (p. 18), read by someone inexperienced in clinical venereology, could give the impression that complications occur much more frequently than they really do. Complications and their treatment must, of course, be described. At the same time it could be made clear that in the vast majority of male patients acute gonorrhoea is diagnosed and effectively treated at the stage of anterior urethritis without difficulty.

The illutrations, on the whole, are effective. The simple line drawings are all that are required for a diagrammatic representation of the distribution of the rash of secondary syphilis (Fig. 44), or the grosser facial characteristics that may be found in congenital syphilitics (Fig. 54). The technique is less successful in depicting more detail: the diagrams of condylomata lata (Fig. 45) and genital warts (Fig. 64) are almost interchangeable, whereas, in practice, differentiation between these conditions is of the greatest importance.

The only jarring feature of this book is in some of the illustrations. About 8 of the 64 are surprisingly naive and would not be out of place in a children's picture book. It is surely unnecessary to illustrate a bottle and syringe over the heading of 'Treatment of syphilis' (Fig. 56). There is an almost identical drawing called 'The treatment of gonorrhoea' as Fig. 13. Similar comments may be made on drawings of tablets and pessaries (Figs. 4 and 26). The inclusion of this type of illustration does not do justice to a serious professional textbook.

These comments on presentation do not alter the fact that this is a well written textbook that offers the medical student or practitioner a sound survey of the subject at an extremely reasonable cost.

\section{Repair and Reconstruction in the Orbital Region}

John Clark Mustarde. Pp. xv +382 , illustrated. Edinburgh and London: E. \& S. Livingstone. 1966. $95 \mathrm{~s}$.

The major part of this work is concerned with replacement of tissue about the eye. Other sections deal with injuries and deformities of the skeleton, the lacrymal apparatus and the lids. Volumes have already been written on these matters, but this is a fresh approach, namely a description of the methods of treatment, with their rationale which have been adopted by one surgeon in the course of a lengthy experience in ophthalmic and plastic surgery. Operations are described clearly, and are illustrated with a wealth of superb photographs and drawings. Many will have felt the need for such a practical book, and will be grateful to the author for his lucid exposition.

\section{Cataract Operation by Enzymatic Zonulolysis}

Hans Hofmann. Translated by D. SHuKri. First American translation edited by $R$. M. Fasanella. Pp. 118, illustrated. New York: Grune and Stratton. London: Bailliere, Tindall and Cassell. 1966. 52s.

This monograph deals with the theoretical and practical aspects of zonulolysis: it is the result of laboratory work by the author and the combined clinical experience of the University eye clinic at Graz Austria. A very comprehensive bibliography is included, and the results of other workers carefully documented. The first half of the book deals with the theoretical aspects of zonulolsyis, considering the enzymes available, their mode of action and the effects which they may have on other ocular tissues. The latter half outlines the techniques of cataract extraction using enzymatic zonulolysis and discusses the indications and complications of the method.

To the practising surgeon two important points stand out, stretching the zonule as an aid to enzyme action, and the inhibitory effect of serum inactivators. The author presents evidence to show that the zonular fibres undergo enzymatic lysis more rapidly and completely in vitro if they are kept under tension, and suggests that the natural tension in the eye should be augmented with an expresser during the period of enzyme action. Alphachymotrypsm is the accepted zonulytic enzyme in Britain, but a case is presented for the use of trypsin which has a high therapeutic ratio. Considerable clinical experience has been gained with this alternative enzyme which appears to be remarkably free of side effects.

The book has been some time on the way, in its present form, so that the recent work on enzyme induced 